\title{
SYNTHESIS AND CHARACTERIZATION OF NANOSCALE HYDROXYAPATITE
}

\author{
Sampaio, G. Y. H. ${ }^{1}$, ; Farias, K. A. S. ${ }^{12 *}$; Lima, R. J. S. ${ }^{1}, 2$; Mendes, L. S. ${ }^{3}$; Carrode- \\ guas, R. G. ${ }^{1}$, ; Fook, M. V. L. ${ }^{1},{ }^{2}$ \\ ${ }^{1}$ CERTBIO,Academic Unit of Materials Engineering, Federal University of Campina Grande, Campina Grande, Paraiba, Brazil \\ ${ }^{2}$ Academic Unit of Physics, Federal University of Campina Grande, Campina Grande, Paraíba, Brazil \\ ${ }^{3}$ Institute of Chemistry, São Pasulo State University, Araraquara, São Paulo, Brazil
}

*kafariascg@gmail.com

Synthetic nanohydroxyapatite (nHA) is a prominent material to be applied in bone tissue engineering devices, due to nHA similarity with the main component of the bone inorganic phase, biocompatibility, biodegradability, and bioactivity. The specific characteristics of the nHA crystals are dependent on the synthesis method. Therefore, the aim of this work was to evaluate the structure of the nHA obtained through chemical precipitation, for the understanding of nHA physico-chemical and biological properties. $\mathrm{nHA}$ was produced by dropwise addition of $1600 \mathrm{~mL}$ of $0.7 \mathrm{M}$ aqueous $\mathrm{Ca}\left(\mathrm{NO}_{3}\right)_{2} \cdot 4 \mathrm{H}_{2} \mathrm{O}(\mathrm{pH} 5.5)$ on $1100 \mathrm{~mL}$ of $0.5 \mathrm{M}\left(\mathrm{NH}_{4}\right)_{2} \mathrm{HPO}_{4}(\mathrm{pH} 10.4$, adjusted with concentrated $\mathrm{NH}_{3}$ ) under stirring at $80^{\circ} \mathrm{C}$. The reaction mixture was aged $24 \mathrm{~h}$ then vacuum filtered and washed with water and ethanol. The precipitated $\mathrm{nHA}$ was dried at $80^{\circ} \mathrm{C}$ for $24 \mathrm{~h}$. The structure obtained nHA was characterized by X-Ray Diffraction and the Rietveld refinement method, Transmission Electron Microscopy and Fourier Transform Infrared Spectroscopy. Preliminary results indicate that the material consisted of calcium deficient hydroxyapatite nanocrystals with lattice parameters $\mathrm{a}=\mathrm{b}=9.43019 \AA$ and $\mathrm{c}=6.88162 \AA$, and $\mathrm{c}$-axis preferentially oriented. Nanoparticles, shaped as rods, presented mean crystallite size of $\sim 21 \mathrm{~nm}(\sim 47 \mathrm{~nm}$ length and $\sim 8 \mathrm{~nm}$ width) and specific surface area of $90.1 \mathrm{~m}^{2} / \mathrm{g}$. According to the obtained results the method of synthesis of nHA seems to be reproducible and effective to prepare large quantities of nHA to be evaluated as biomaterials. 